\title{
Spanish awards rekindle old rivalries
}

\section{Infrastructure programme steers substantial resources to major cities, upsetting some regional centres.}

An ambitious effort to develop Spanish universities into campuses that are among Europe's best has stoked some long-standing regional rivalries.

On 26 November, the government announced which universities would benefit from the inaugural round of an annual programme called the Campus of International Excellence, administered jointly by the Ministry of Science and Innovation and the Ministry of Education. The €150-million (US\$226-million) scheme is designed to steer resources, in the form of government seed money and loans, to the strategic infrastructure projects with the most potential to aid teaching and research.

But with $€ 73$ million of this year's financing going to just five proposals from institutions in Madrid and Barcelona, the awards have already provoked complaints of regional bias in a country that has a long history of wrangling over the way that resources tend to be channelled towards its metropolitan centres.

Following the Ministry of the President's announcement of the competition on 23 July, an initial selection round saw 51 entrants share $€ 53$ million in seed funding to develop their proposals. The 18 winners were then divided into three tiers: the five Campuses of International Excellence; four Regional Campuses of Excellence, which share $€ 30.1$ million; and nine Promising Projects, mostly awarded between $€ 2$ million and $€ 4$ million (see graphic).

Regional universities dominate this lowest tier. "We're discouraged," says agricultural engineer Juan Julía Igual, rector of the Polytechnic University of Valencia, which won

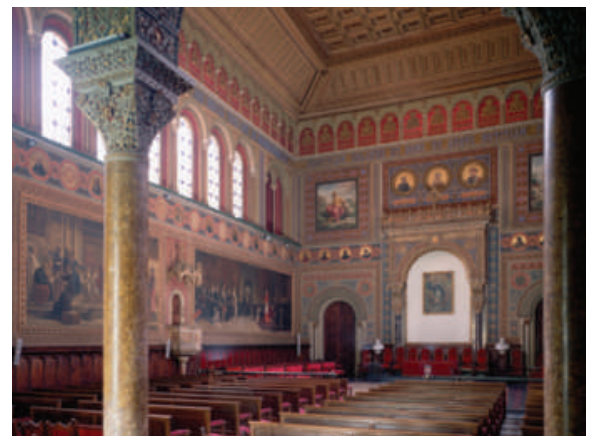

A University of Barcelona project has won the status of 'Campus of International Excellence'.

a total of $€ 8$ million for its plan to create a campus based around health and sustainability research. "The goal is positive, but the way it proceeded is unacceptable."

Julía Igual is particularly critical of the labelling system used to rank the proposals. "Classifying institutions as Promising Projects makes us sound almost like the junior football leagues," he says. "Valencia Polytechnic appears ahead of its Madrid and Barcelona equivalents in international rankings, so I find it hard to believe that they were the only Spanish campuses of international excellence."

\section{Call for transparency}

Julía Igual says that in the future, the government should use a more transparent competition system that is based on international ranking models, and it should raise the overall budget. "The funding agencies need to recognize the same reality the international rankings do." However, Ministry of Education spokesman Fernando Herranz counters that "the objective of this plan was not to create another ranking". And responding to the charges of regional bias, he adds that "with more than 50 applicants, not everybody can win".

María José Alonso, vice-rector for research at the University of Santiago de Compostela, is involved in the university's $€ 150$-million 'Campus of Life' campaign. The project was awarded $€ 7.5$ million, she thinks, because it focuses on the institute's strongest disciplines and draws in its neighbours and other agencies. "It was obvious we weren't going to win it all from this ministry call," she says. Despite the modest size of the award, she says, "we understand it is a stimulus and a stamp of approval from the central government. It will help us negotiate with the regional government for even more support," she says.

The goal of creating centres of excellence was partly inspired by Germany's Excellence Initiative, a competition between universities to win elite status that recently had its $€ 2$.7-billion budget for the period 2012-17 confirmed (see Nature 462, 24; 2009).

But the programmes have different goals, says Matthias Kleiner, who oversees Germany's excellence initiative and is president of the nation's Research Foundation (DFG). Kleiner, who was a member of the international committee asked to evaluate the Spanish proposals, points out that the German initiative focuses on research, whereas teaching is a very important part of the Spanish one.

Lucas Laursen

\section{BUILDING EXCELLENCE}

Spanish universities in Barcelona and Madrid have taken the lion's share of the funding in the government's plan to create Campuses of International Excellence.

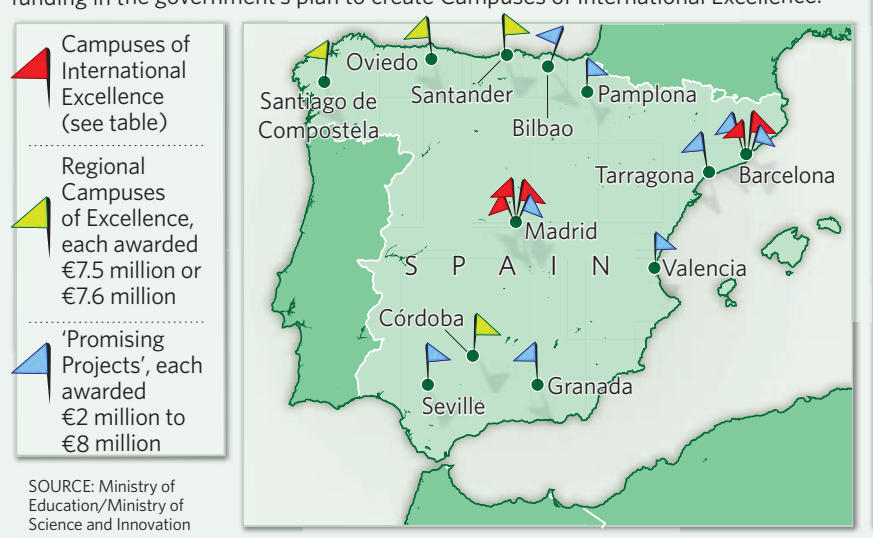

PREMIER PROJECTS Project

Barcelona Knowledge Campus

University City in Moncloa: Campus of International Excellence of the Community of Madrid

Charles III Campus

UAB Campus of International Excellence: Betting on Knowledge and Innovation

Campus of International Excellence UAM-CSIC

\section{Universities}

University of Barcelona \&

Polytechnic University of Catalonia

Financing (€ million)

Complutense University of

Madrid \& Polytechnic University

of Madrid

Charles III University of Madrid

Autonomous University

of Barcelona (UAB)

Autonomous University

of Madrid (UAM)
21 